\title{
A Comparison of Different Methods of Assessing and Calculating Blood Pressure Variability Post-Stroke or TIA
}

\author{
Davison WJ, Myint PK, Potter JF.
}

\section{Introduction}

Blood pressure variability (BPV) is a cardiovascular risk factor independent of mean blood pressure (BP). ${ }^{1-2}$ However, there is currently no consensus regarding its measurement and calculation. BPV is most commonly reported as the standard deviation (SD), ${ }^{2}$ but as SD is related to the mean value other indices have been proposed. ${ }^{3-4}$ For long-term visit-to-visit BPV there is strong correlation between different indices, ${ }^{4-5}$ but this may not be the case for shorter-term measurements where the index accounts for the time series of measurements.

\section{Methods}

- Adults with TIA/stroke (NIHSS<15) were recruited between 72 hours and 12 weeks post-event.

- All participants had 10 minutes of beat-to-beat BP monitoring (Task Force ${ }^{\circledR}$ Monitor), at rest in the supine position ( $\geq 5$ minutes valid recording) and daytime ambulatory BP monitoring ((ABPM) SpaceLabs 90207) with BP measured at 20 minute intervals ( $\geq 14$ readings).

- A subset also completed self-BP monitoring (SBPM) at home over 7 days (Omron 705IT), taking 2 readings every morning and evening, seated at rest, before meals and antihypertensive medications ( $\geq 21$ readings).

- For each set of measurements BPV of systolic BP (SBP) and diastolic BP (DBP) were calculated as the SD, coefficient of variation ((CV) $100 \mathrm{x}$ $\mathrm{SD} /$ mean), average real variability ((ARV) mean of the absolute difference between successive BP measurements), and maximum-minimum difference ((MMD) maximum BP minus minimum BP).

- Data were analysed using SPSS (v.23.0). For each measurement method BPV indices were compared using Pearson's correlation coefficient. Participants were divided into quartiles for each index and the agreement of classification by quartile was assessed using the kappa statistic.

\section{Results}

- 158 participants with 95 in the SBPM subset.

- SD, CV, and MMD of SBP were strongly correlated for all measurement methods.

- ARV of SBP was strongly correlated with other indices for SBPM, but relationship strengths decreased as the time between BP measurements reduced.

- Findings for DBP were the same (data not presented).

\begin{tabular}{|l|l|}
\hline Age (years) & $73.6(10.0)$ \\
\hline Sex (male) & $104(66 \%)$ \\
\hline Diagnosis (TIA) & $106(67 \%)$ \\
\hline Time to recruitment (weeks) & $9.1(3.2)$ \\
\hline Clinic SBP (mmHg) & $151.6(19.4)$ \\
\hline Clinic DBP (mmHg) & $83.7(11.9)$ \\
\hline Antihypertensive treatment & $147(93 \%)$ \\
\hline
\end{tabular}

Table 1: Demographics, presented as mean (SD) or count (\%).
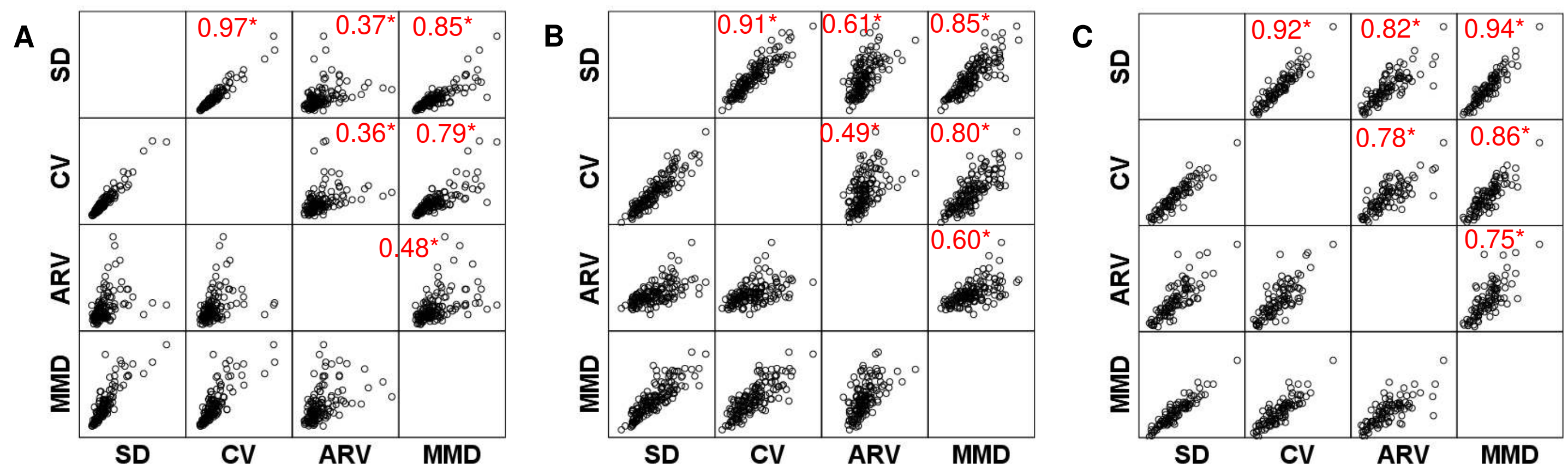

Figure 1: Scatter plot matrices to show correlations of BPV indices for each BP measurement method. A is beat-to-beat.

B is daytime ABPM. C is SBPM. Numbers displayed are Pearson's $r$ values. ${ }^{*} p<0.01$

\begin{tabular}{|c|c|c|c|c|c|c|c|c|c|}
\hline & \multicolumn{3}{|c|}{ Beat-to-beat } & \multicolumn{3}{|c|}{ Daytime ABPM } & \multicolumn{3}{|c|}{ SBPM } \\
\hline & CV & ARV & MMD & CV & ARV & MMD & CV & ARV & MMD \\
\hline SD & $\begin{array}{c}0.62 \\
(0.52- \\
0.71)^{*}\end{array}$ & $\begin{array}{c}0.22(0.11- \\
0.32)^{*}\end{array}$ & $\begin{array}{c}0.57(0.46- \\
0.67)^{*}\end{array}$ & $\begin{array}{c}0.63(0.53- \\
0.72)^{*}\end{array}$ & $\begin{array}{c}0.33(0.22- \\
0.43)^{*}\end{array}$ & $\begin{array}{c}0.46(0.36- \\
0.57)^{*}\end{array}$ & $\begin{array}{c}0.65(0.51- \\
0.76)^{*}\end{array}$ & $\begin{array}{c}0.43(0.29 \\
0.55)^{*}\end{array}$ & $\begin{array}{c}0.57(0.44- \\
0.68)^{*}\end{array}$ \\
\hline CV & - & $\begin{array}{c}0.21(0.10- \\
0.32)^{*}\end{array}$ & $\begin{array}{c}0.47(0.37- \\
0.57)^{*}\end{array}$ & - & $\begin{array}{c}0.20(0.10- \\
0.30)^{*}\end{array}$ & $\begin{array}{c}0.39(0.29- \\
0.50)^{*}\end{array}$ & - & $\begin{array}{c}0.39(0.25- \\
0.52)^{*}\end{array}$ & $\begin{array}{c}0.47(0.33- \\
0.59)^{*}\end{array}$ \\
\hline ARV & & - & $\begin{array}{c}0.25(0.13- \\
0.35)^{*}\end{array}$ & & - & $\begin{array}{c}0.32(0.20- \\
0.42)^{*}\end{array}$ & & - & $\begin{array}{c}0.45(0.32- \\
0.58)^{*}\end{array}$ \\
\hline
\end{tabular}

Table 2: Agreement of classification by quartiles of variability for different indices of SBP within each method of BP measurement. Data presented are kappa statistic (95\% confidence interval). ${ }^{*} p<0.01$.

\section{Conclusions}

- Different BPV indices are highly correlated, but relationships with ARV are affected by the timescale of measurements.

- Deriving multiple indices of BPV from a set of measurements is unlikely to provide additional information.

- The most appropriate method of calculating BPV may depend upon the timescale of BP measurement.

- Further data regarding the prognostic value of different indices would help to standardise the calculation of BPV. 